\title{
Control by an Identified Modulatory Neuron of the Sequential Expression of Plateau Properties of, and Synaptic Inputs to, a Neuron in a Central Pattern Generator
}

\author{
Frédéric Nagy, ${ }^{1}$ Patsy S. Dickinson, ${ }^{2}$ and Maurice Moulins ${ }^{1}$ \\ 'Laboratoire de Neurobiologie et Physiologie Comparées, 33120 Arcachon, France, and 'Department of Biology, Bowdoin \\ College, Brunswick, Maine
}

\begin{abstract}
Recordings from the lateral gastric (LG) neuron, which forms part of the gastric mill central pattern generator in the red lobster, Palinurus vulgaris, indicate that regenerative membrane properties (plateau properties) and synaptic inputs interact sequentially rather than simultaneously to determine its discharge pattern. LG thus presents a composite discharge, consisting of 2 separate segments of firing and one silent period. The first firing segment depends on regenerative membrane properties; this is the endogenous component, or segment, of LG's discharge. The second firing segment is the result of extrinsic synaptic input, forming the synaptic component of LG's discharge. The relative importance of these 2 components can vary, and thus LG's discharge ranges from one in which LG fires only as a result of its endogenous component to one in which its endogenous component is entirely absent and only the synaptic component underlies action potentials. Activity in an identified modulatory neuron suppresses the endogenous segment and enhances the synaptic segment of LG's discharge. This long-lasting effect in turn changes phase relationships within the gastric mill network and provides mechanisms for producing flexibility in the gastric pattern generator and for ensuring that a specific motor output is generated by a flexible neural network.
\end{abstract}

In a number of systems, neurons that are members of central pattern generators (CPGs) have been shown to possess regenerative membrane properties that aid in the production of bursts of action potentials (for review, see Selverston and Moulins, 1985). Synaptic interactions, which can differ in both strength and time course among the various neurons within a network, are important in coordinating the firing of these neurons (Hartline, 1979; Eisen and Marder, 1982, 1984). Pattern generation, including the sequence in which the various neurons fire, the duration and intensity of their bursts, and the correct timing of each neuron's activity cycle, is thus determined by the interaction of the endogenous membrane properties and the synaptic relations within a network (Weeks, 1981; Getting, 1988; Miller, 1987; see Selverston and Moulins, 1985, 1987, for reviews).

\footnotetext{
Received July 9, 1987; revised Dec. 14, 1987; accepted Dec. 15, 1987

We thank Eve Marder for critical reading of the manuscript and H. G. Heinzel for useful discussions. This work was supported by a Ministère de la Recherche et Technologie grant (85C1152) to M.M., an American Heart Association Maine Affiliate Grant-in-Aid to P.S.D., a Bowdoin College grant to P.S.D., and a NATO grant (RG86/0540) to Eve Marder.

Correspondence should be addressed to Patsy S. Dickinson, Bowdoin College, Brunswick, ME 04011.

Copyright (C) 1988 Society for Neuroscience $0270-6474 / 88 / 082875-12 \$ 02.00 / 0$
}

We have been studying a motor neuron of the gastric mill CPG in the red lobster, Palinurus vulgaris, in which these same 2 factors, regenerative properties and synaptic inputs, interact in a novel way. In this neuron, the lateral gastric (LG) neuron, the depolarizations that result from cndogenous properties and from synaptic inputs are distinct cellular events that occur sequentially, resulting in a "composite discharge" of the LG neuron.

The gastric mill motor pattern is determined by multiple factors, including regenerative membrane properties in many of the component neurons, extensive synaptic interactions between these neurons and extrinsic rhythmic input from other neuronal centers (Mulloney and Selverston, 1974a, b; Selverston and Mulloney, 1974; Selverston et al., 1976; Robertson and Moulins, 1981, 1984; Russell, 1985a, b, 1987). The motor pattern itself can be broken down into 2 subsystems, each with 2 phases (a power and a return stroke); the subsystems interact in such a manner that they are generally slightly out of phase with one another (Mulloney and Selverston, 1974b; Kussell and Hartline, 1984). These subsystems control the lateral teeth and the medial tooth of the gastric mill. The LG ncuron plays a kcy rolc in the coordination of the subsystem controlling the lateral teeth, and in coordinating the relationships of the 2 subsystems (Russell, 1985b, 1987).

Because $L G$ does play a key role in the coordination of the gastric mill network, its composite form of discharge is of particular interest. The 2 components, endogenous properties and synaptic input, which contribute sequentially to the composite discharge, can vary in relative importance. This alteration has profound effects on the form and timing of the LG discharge. This variability is sufficient to account for a great deal of the flexibility observed in the output of the motor system. Furthermore, we show here that the relative importance of these 2 components of LG's discharge can be altered by an identified modulatory neuron, the anterior pyloric modulator (APM; Nagy et al., 1981), which can also elicit or activate the gastric rhythm (Dickinson et al., 1987). The APM neuron, by decreasing one component and increasing the other, is able to provoke dramatic changes in the form of LG's composite discharge. Because LG plays a key role in coordinating the rhythm, such changes in turn produce substantial changes in the behavior controlled by the network.

\section{Materials and Methods}

Experiments were performed on male and female red lobsters, Palinurus vulgaris, ranging in size from 300 to $1000 \mathrm{gm}$. Lobsters were maintained in aerated, running sea water (temperature $16-20^{\circ} \mathrm{C}$ ) for up to 4 weeks before use. 

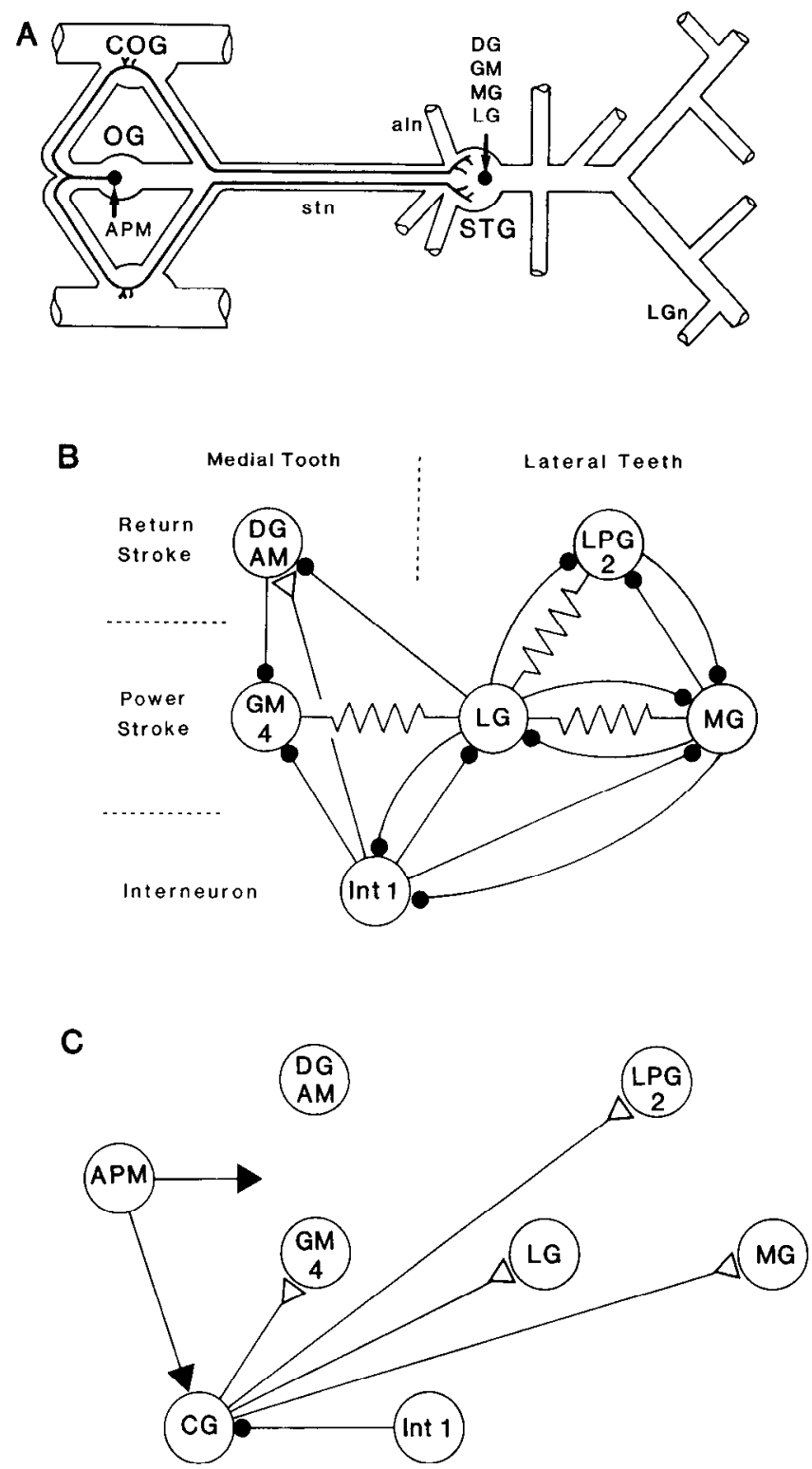

Figure 1. The stomatogastric nervous system, the gastric mill network, and the anterior pyloric modulator neuron $(A P M) . A$, Schematic drawing of the isolated preparation. $B$, The gastric mill neuronal network, indicating the power and return stroke motor neurons for each of the 2 subsystems (lateral, medial) and the single interneuron. $C$, Extrinsic inputs to the gastric circuit. Symbols: filled circles, inhibitory chemical synapses; open triangles, excitatory chemical synapses; arrows, activating synapses of unspecified type; resistor symbols, electrical coupling. Abbreviations: aln, anterior lateral nerve; $A M$, anterior median neuron; $C G$, commissural gastric neuron; $C O G$, commissural ganglion; $D G$, dorsal gastric neuron; $G M$, gastric mill neuron; Int 1 , interneuron 1 ; $L G$, lateral gastric neuron; $L G n$, lateral gastric nerve; $L P G$, lateral posterior gastric neuron; $M G$, median gastric neuron; $O G$, esophageal ganglion; $S T G$, stomatogastric ganglion; stn, stomatogastric nerve.

The stomatogastric nervous system-including the stomatogastric ganglion (STG), paired commissural ganglia (COGs), and the oesophageal ganglion (OG), together with the connecting nerves (Fig. 1A)-was dissected out in cool, aerated saline (composition in $\mathrm{mm} /$ liter: $\mathrm{NaCl}$, $479.12 ; \mathrm{KCl}, 12.74 ; \mathrm{MgSO}_{4}, 10.0 ; \mathrm{Na}_{2} \mathrm{SO}_{4}, 3.91 ; \mathrm{CaCl}_{2}, 13.67 ; \mathrm{HEPES}$, $5.0 ; \mathrm{pH} 7.45$ ) and pinned in a Sylgard-covered petri dish. (For further details of the dissection, see Moulins and Nagy, 1981.) The ganglia were desheathed to allow access to the neuronal somata. The preparation was maintained at $17^{\circ} \mathrm{C}$ with a Peltier cooling cell and was superfused with fresh, oxygenated saline throughout each experiment.
Intracellular recordings were made from neuronal cell bodies using glass microelectrodes filled with $3 \mathrm{M} \mathrm{KCl}$ or $2 \mathrm{M} \mathrm{K}$ acetate (resistances, with thin-walled glass capillary tubing, of 10-20 M $\Omega$ ) and World Precision Instruments microprobe systems (WPI M707). Current was injected into neurons through the recording electrodes via a bridge circuit. Platinum wire electrodes were used for extracellular recordings from the various nerves of the preparation. Individual motor neurons were identified by the presence of action potentials in identified motor nerves (Maynard and Dando, 1974); a consideration of synaptic relationships within the gastric network helped confirm the identities (Mulloney and Selverston, 1974a, b; Selverston and Mulloney, 1974; Selverston et al., 1976; Mulloney, 1987; Selverston, 1987; see Fig. 1, $B, C$ ). The APM was identified by the presence of axons in the inferior esophageal nerves (ions), the superior esophageal nerves (sons), and the stomatogastric nerve $(s t n)$, as well as by its characteristic effects on the pyloric and gastric networks (Nagy and Dickinson, 1983; Dickinson et al., 1987).

\section{Results}

Regenerative properties and synaptic inputs determine a composite discharge in the lateral gastric neuron $L G$

In the gastric mill CPG of the stomatogastric ganglion in the red lobster, the regenerative properties of a motor neuron, the LG neuron, interact with synaptic input to the LG neuron in a novel manner. The pattern of activity in the LG neuron can be considered as a composite discharge: it results from the sequential occurrence of 3 cellular events, which can be used to divide LG's period into 3 distinct phases (Fig. 2, phases $a-c$ ). During the first phase, LG depolarizes rapidly; the membrane potential reaches a peak during this phase, and a high-frequency volley of action potentials is produced. At the end of phase $a$, the membrane potential drops somewhat, though it can rcmain above threshold throughout much or all of the second phase (Fig. 2A, phase $b$ ). Distinct epsps can be seen throughout this second phase. At the end of phase $b$, the epsps stop and the membrane potential always drops below threshold, producing a silent period (Fig. $2 A$, phase $C$ ). When the CPG is active, this cycle is repeated with a period of $4-5 \mathrm{sec}$.

The first 2 of these sequential phases, both of which can give rise to action potentials, are distinct events, as is indicated by the fact that they are separable. This is seen in Figure 3, in which hyperpolarizing current was injected into LG during ongoing activity. In the absence of injected current (Fig. $3 A$ ), both components of LG's discharge are large, and action potentials are generated throughout both phases. However, as LG is progressively hyperpolarized (Fig. 3, B, C), phase $a$ increases in amplitude and continues to generate a high-frequency burst of spikes. In contrast, the number and frequency of spikes generated during phase $b$ decreases (Fig. $3 B$ ); ultimately, no spikes are generated during this phase (Fig. $3 C$ ).

In an attempt to understand the composite firing pattern of LG and its variants, we analyzed the cellular events underlying each of these phases. The first phase appears to result largely from endogenous membrane properties which give rise to regenerative depolarizations, or plateau potentials (Russell and Hartline, 1978), as is shown in Figure 4. Figure $4 A$ shows that the depolarization seen in phase $a$ can be provoked earlier than normal (i.e., during phase $c$ ) by the intracellular injection of brief (100-200 msec) pulses of depolarizing current. The epsps seen during phase $b$ thus begin only after the plateau in LG has terminated (compare with Fig. 2). Furthermore, similar hyperpolarizing pulses injected during phase $a$ can cut short this plateau (Fig. $4 B$ ). Additional evidence that phase $a$, but not phase $b$, results from an endogenous depolarization of the $L G$ neuron comes from the experiments described above, in which the am- 

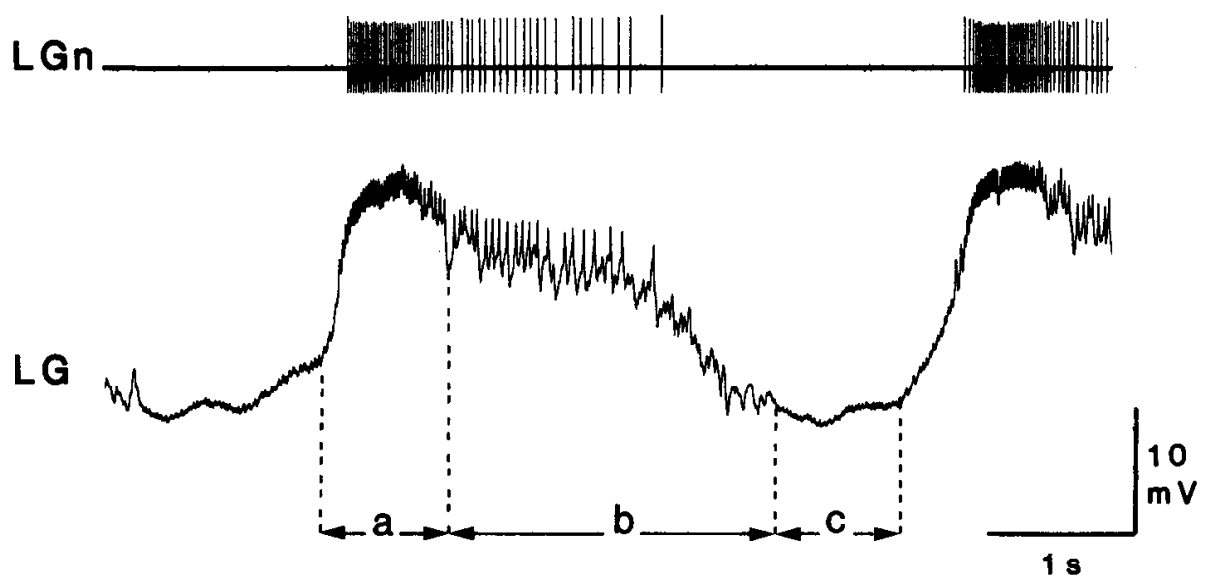

Figure 2. Composite discharge of the LG neuron. Three phases, labeled $a-c$, are clearly distinguishable. The spike frequencies that characterize each firing phase (high in phase $a$, moderate in phase $b$ ) are more obvious in the extracellular (upper) trace. Calibrations: horizontal bar, $1 \mathrm{sec}$; vertical bar, 10 $\mathrm{mV}$.

plitude of the plateau increases but spike frequency remains relatively constant as LG is experimentally hyperpolarized. Together, these results indicate that during phase $a$, the depolarization of the LG neuron is, in fact, a plateau potential, which results from the activation of regenerative membrane properties. We have therefore called phase $a$ the endogenous segment, or component, of LG's discharge.

The second phase $(b)$ of the LG discharge relies heavily upon excitatory synaptic input. This phase, during which a barrage of epsps can be seen, always occurs at the same time as a barrage of epsps in another neuron of the gastric pattern generator, the gastric mill (GM) motor neuron (Fig. $5 \mathrm{~A}$ ). These epsps are also seen simultaneously in 2 other gastric neurons, the median gastric (MG) and lateral posterior gastric (LPG) neurons (Fig. 5, $B$, $C)$. Such a rhythmic barrage of simultaneous epsps in these 4 neurons is known to come from the commissural gastric (CG) neuron, a member of the commissural gastric oscillator which helps drive the gastric rhythm (Robertson and Moulins, 1981,
A
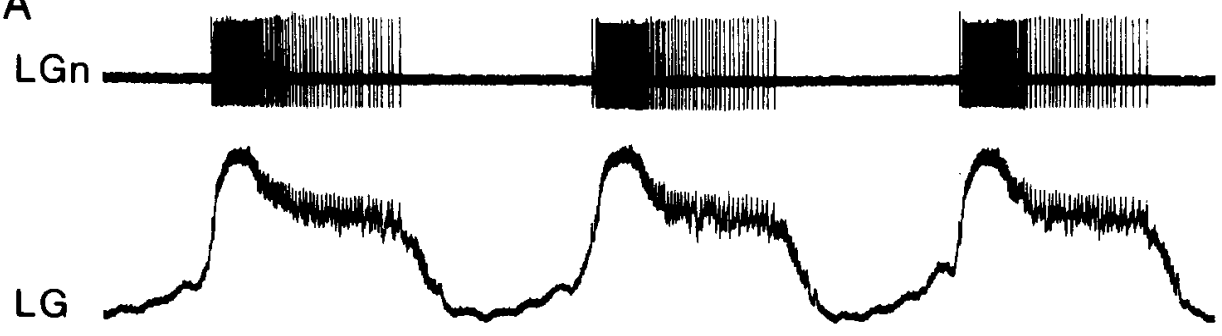

\section{O $\mathrm{AA}$}

B

LGn
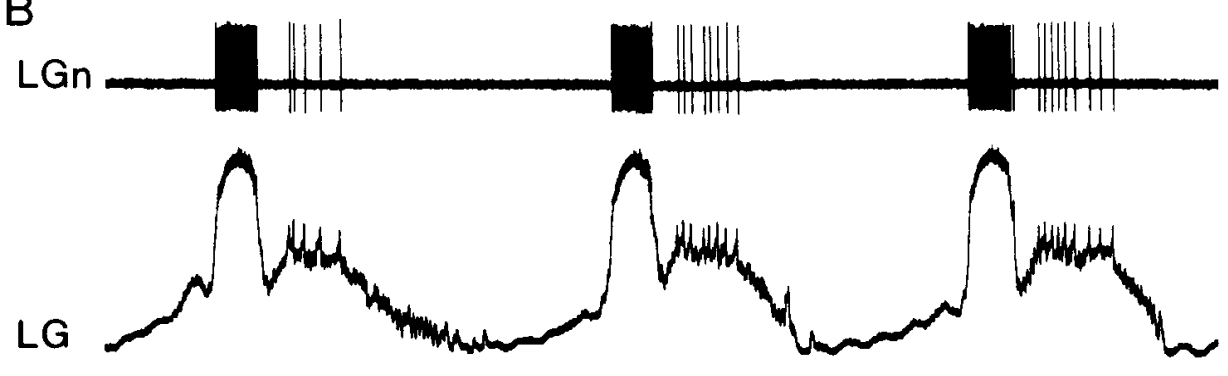

$-2 n A$

C
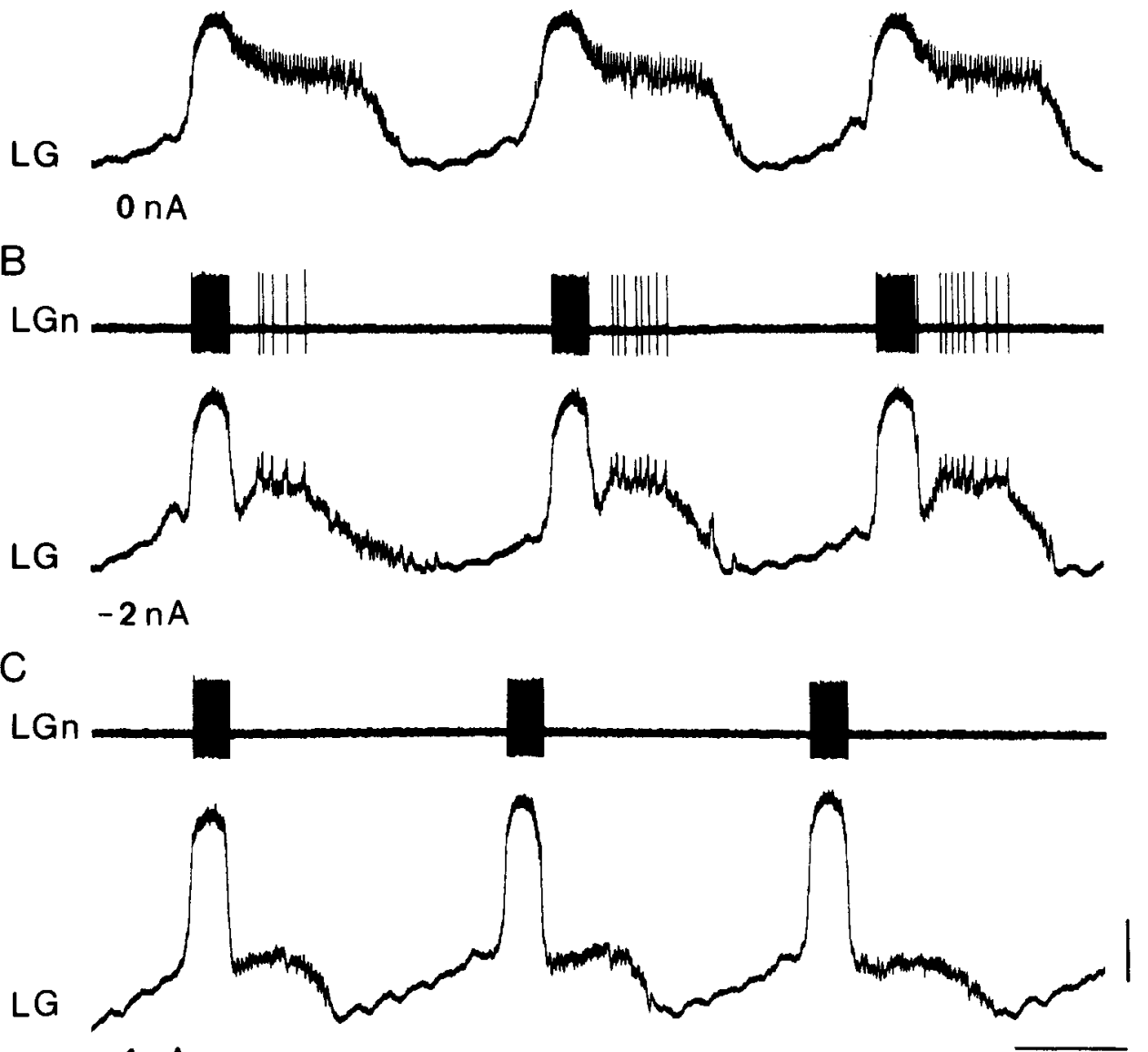

$-4 n A$
Figure 3. The 2 phases of LG's discharge can be separated by experimentally hyperpolarizing LG. Constant hyperpolarizing current injected into $L G$ causes an increase in the amplitude of phase $a$, but no change in the duration or firing frequency of the resultant burst of action potentials, indicating that this phase is an endogenous depolarization. In contrast, spiking in phase $b$ decreases with increasing hyperpolarization. $A$, No current injected. $B,-2 \mathrm{nA}$ current in LG. $C,-4 \mathrm{nA}$ current in LG. Calibrations: horizontal bars, $2 \mathrm{sec}$; vertical bars, $10 \mathrm{mV}$. 

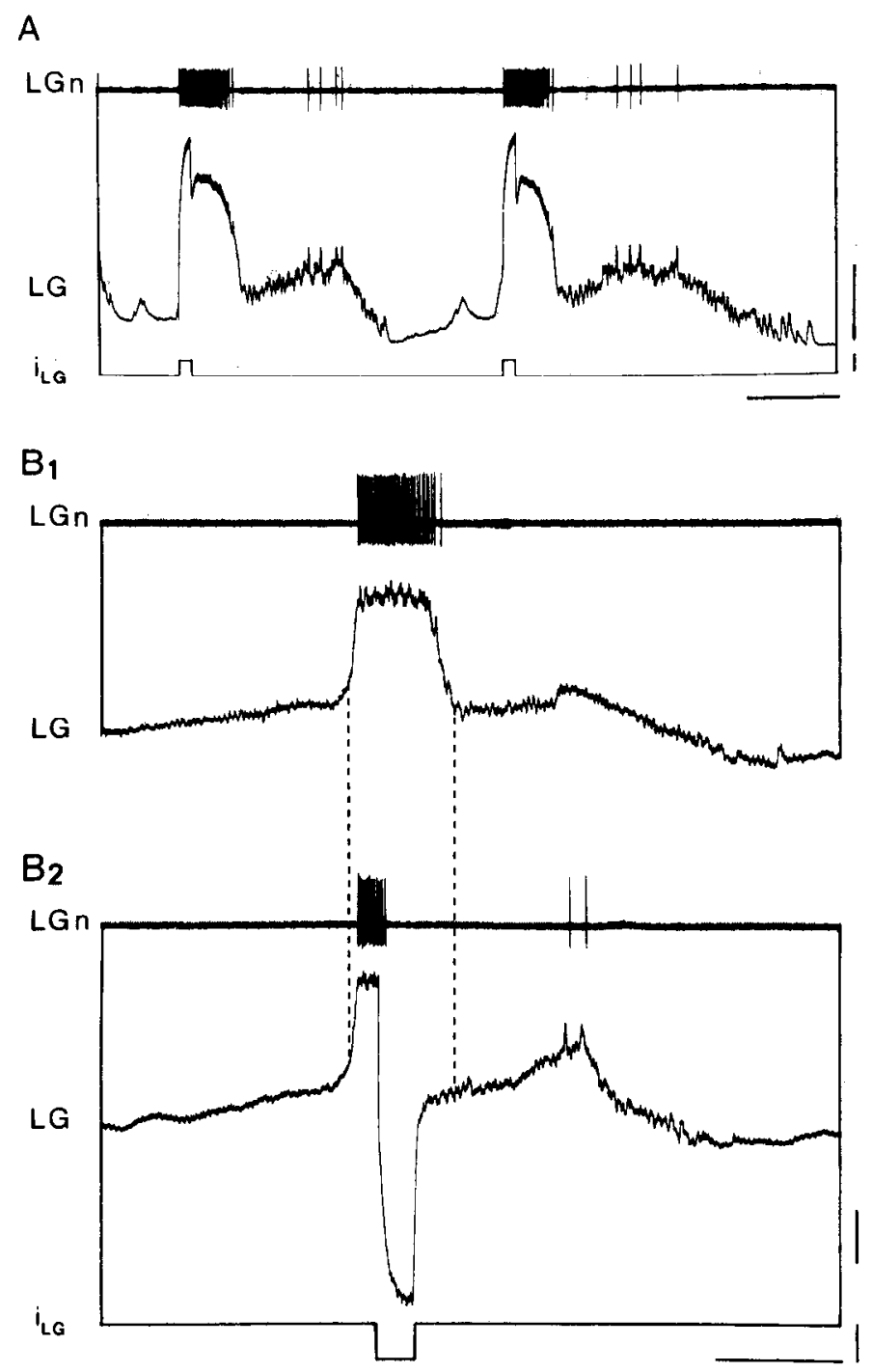

Figure 4. A plateau potential underlies phase $a$ of LG's discharge. $A$, Phase $a$ can be triggered by a brief $(200 \mathrm{msec}, 2 \mathrm{nA})$ pulse of depolarizing current $\left(i_{r_{G}}\right)$ injected into the soma of LG. After the termination of the plateau, a small barrage of synaptic potentials occurs, causing 4 additional action potentials. $L G n$, extracellular trace. $B$, Similar hyperpolarizing pulses ( $\mathrm{i}_{\mathrm{LO}}, 300 \mathrm{msec},-2.8 \mathrm{nA}$ ) injected during phase $a$ can cut short the plateau. (Compare the total lengths of the plateaus in $B 1$ and $B 2$; dotted lines.) Calibrations: horizontal bars, $1 \mathrm{sec}$; vertical bars, 10 $\mathrm{mV}, 2 \mathrm{nA}$ in $A, 3 \mathrm{nA}$ in $B$.

1984) and which may be homologs of the E cells previously described in Panulirus (Russell, 1976; see also Dickinson et al., 1987). The synaptic nature of phase $b$ of LG's discharge is corroborated by the hyperpolarization of LG (Fig. 3). As LG is hyperpolarized (Fig. 3, B, C), the synaptic potentials no longer bring it above threshold during phase $b$; action potentials decrease in frequency and finally cease altogether, and the synaptic potentials underlying $L G$ 's discharge during this phase become evident. Thus, the most important cellular event underlying phase $b$ of LG's discharge is the barrage of excitatory synaptic potentials it receives from the CG neuron or E cell. We therefore called phase $b$ the synaptic segment, or component, of LG's discharge.

The third phase (c), which constitutes the silent phase of LG's cycle, is also largely the result of synaptic input. During this phase, LG is inhibited by another neuron within the network, Int 1 (Selverston et al., 1976). Although the ipsps are difficult to distinguish individually, they can be seen in some recordings; in these cases they correspond to the concomitant inhibition of the GM neuron by Int 1 (see Fig. 5A). We will not consider this phase further.

One important aspect of LG's composite discharge is the fact that the relative importance of the endogenous and synaptic components that support this discharge can vary (Figs. 3, 6). As is shown in Figure 6, $A-D$, LG's discharge can vary spontaneously from one in which the endogenous component strongly predominates (Fig. $6 \mathrm{~A}$ ), through a range of intermediates (Fig. $6, B, C)$, to one in which the plateau phase is entirely absent and action potentials occur only during the synaptic segment (Fig. 6D). Here, it can be seen that changes in the relative importance of the 2 components influence not only the shape of the depolarization in LG, but also the duration of its burst of action potentials, spike frequency within the burst, and the patterns or changes in spike frequency that take place during a burst. These patterns range from a moderately uniform spike frequency (seen when a single component strongly dominates the other; Fig. $6, A, D$ ) to patterns in which spike frequency decreases gradually or abruptly during the burst (Fig. $6, B, C$ ) to a completely double burst (Fig. $6 E$ ). In the latter case, the endogenous and synaptic components are separated in time to the extent that a silent period intervenes and LG presents a double burst (Fig. $6 E$ ). As in the other patterns, spike frequency is higher during the endogenous segment than during the synaptic segment of LG's discharge.

Because of the magnitude of the changes that result when the relative importance of the endogenous and synaptic components of LG's composite discharge are altered, we have begun to consider both the control of LG's discharge and the functional implications of changes in such a composite discharge.

\section{Functional implications of $L G$ 's composite discharge}

We first consider the functional consequences of LG's composite discharge. In this context, it is important to remember that LG is both a motor neuron and a member of the gastric mill CPG. The gastric mill CPG is composed of 2 subsets of neurons, one subsystem driving the movements of the 2 lateral teeth, the other controlling the single medial tooth (see Fig. $1 B$; Mulloney and Selverston, 1974a; Selverston and Mulloney, 1974). The LG motor neuron is 1 of 2 neurons driving the power stroke of the lateral teeth. Synapses within each neuronal subset ensure alternation of the power and return stroke motor neurons; interactions between the 2 subsystcms via the interncuron, Int 1 , are largely responsible for determining the phase relationships between the 2 subsystems (Mulloney and Selverston, 1974b; Russell, 1985b, 1987). These relative phases can, however, vary over a considerable range, as is shown in Figures 7 and 8. Changing the form of LG's composite discharge from one in which the endogenous component is strong (Figs. $7 B, 8 A$ ) to one in which it is absent (and the synaptic component is thus dominant; Figs. $7 C, 8 B$ ) alters phase relationships of neuronal discharges both within the lateral tooth subsystem and between the lateral and medial tooth subsystems.

The LG motor neuron interacts with the other power stroke neuron for the lateral teeth, the median gastric neuron, $\mathrm{MG}$, via both electrical coupling and reciprocal inhibition (Fig. $7 \mathrm{~A}$; Mulloney and Selverston, 1974a). In addition, both LG and MG are activated by the CG neuron (see Figs. $1 C, 7 A$ ), which to- 

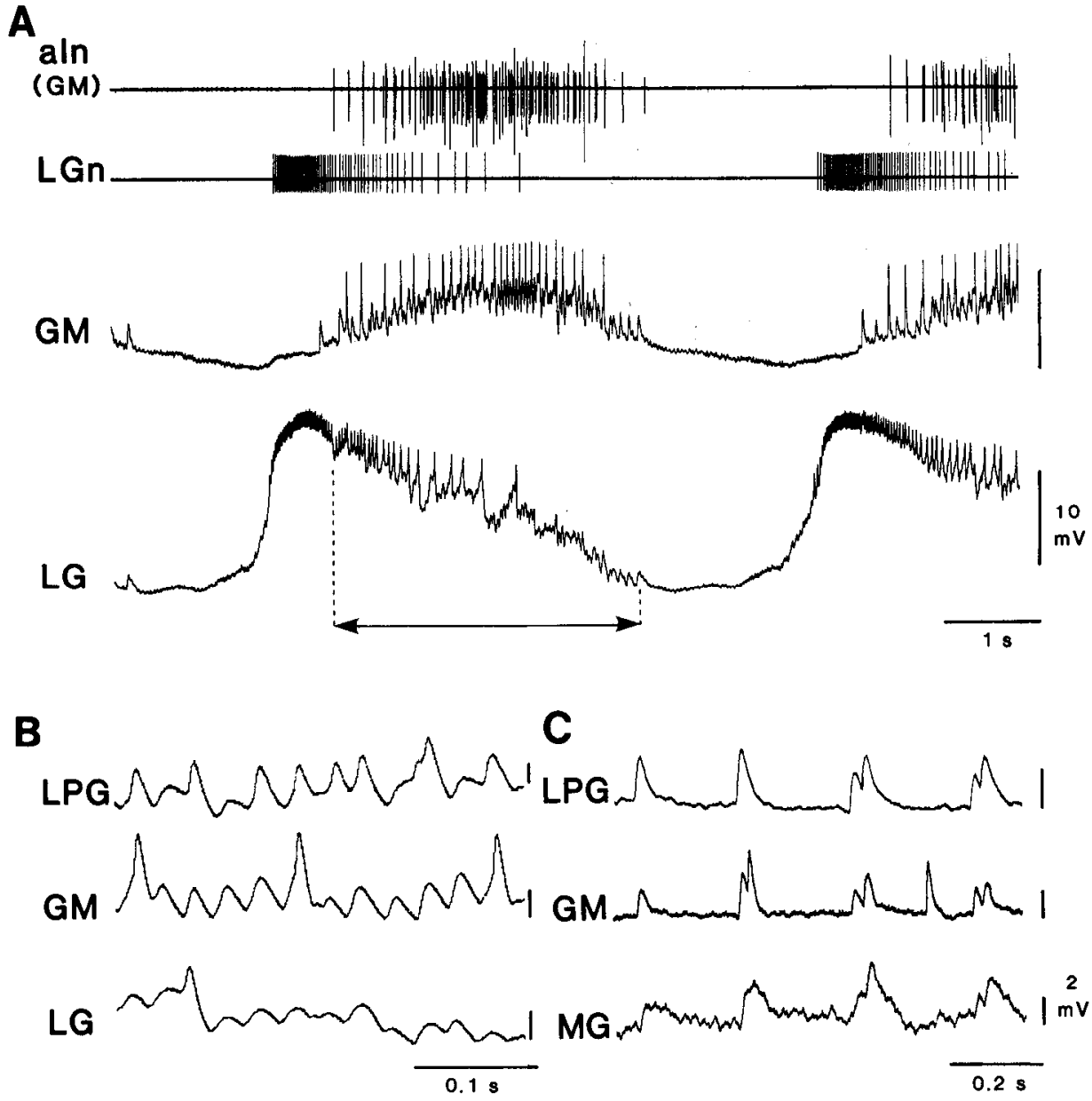

Figure 5. Phase $b$ of LG's discharge results largely from synaptic activation of the LG neuron; it represents the synaptic component of LG's discharge. $A$, Phase $b$ occurs concurrently with the barrage of epsps in the GM neuron. The 2 neurons receive the same epsps; the last 4 synchronous epsps are particularly evident. aln, extracellular recording of the activity of the $4 \mathrm{GM}$ neurons. $B$ and $C$, the epsps that underlie the synaptic phase $(b)$ of LG's discharge occur simultaneously in the LG, GM, LPG, and MG neurons, indicating that they come from the CG neuron (Robertson and Moulins, 1981), which helps drive the gastric rhythm. These recordings (simultaneous in each panel) were taken during phase $b$ of the LG discharge. Calibrations: horizontal bars, 1 sec in $A, 0.1 \mathrm{sec}$ in $B, 0.2 \mathrm{sec}$ in $C$; vertical bars, $10 \mathrm{mV}$ in $A, 2 \mathrm{mV}$ in $B$ and $C$. gether with the electrical coupling, tends to synchronize their firing. At the same time, the reciprocal inhibition promotes outof-phase firing. When the endogenous component of LG's discharge is strong (Fig. $7 B$ ), the inhibitory connections predominate, and LG firing considerably precedes MG firing. During its endogenous segment, LG is considerably depolarized and fires at a high enough frequency to silence $\mathrm{MG}$ entirely. At the end of LG's endogenous segment, $\mathrm{MG}$ is again able to fire; it rebounds, and in some cases can temporarily silence $L G$. This further separates LG's endogenous and synaptic firing segments and produces a slight double burst in LG. In contrast, when LG's endogenous component is absent, and it fires only during its synaptic segment, spike frequency is never high enough to inhibit MG effectively (Fig. 7C). In this case, the electrical coupling and common synaptic input functionally predominate and the 2 neurons fire synchronously. Thus, when LG's discharge includes an endogenous segment, the 2 neurons $\mathrm{LG}$ and $\mathrm{MG}$ are out of phase; when the endogenous component is absent, they fire in phase.

A similar phase shift between the lateral and medial tooth subsets also results from a change in the relative importance of the 2 components of LG's composite discharge. When the endogenous component predominates, the lateral tooth neuron LG begins firing nearly $1 \mathrm{sec}$ before the corresponding medial tooth neuron, GM (Fig. $8 A$ ). When the synaptic phase predominates, however, the power stroke neurons (LG and $G M$ ) of the 2 subsystems begin firing together (Fig. 8B). Becausc the cvolution of spike frequency within LG bursts is changed when the relative importances of the endogenous and synaptic components are altered, the LG-GM phase shift may be functionally even more important than would be predicted on the basis of the shift in the beginnings of the LG and GM bursts. Although there is some overlap between the LG and GM discharges, when LG's endogenous component is strong, its maximum spike frequency occurs during its endogenous depolarization, before GM has begun to fire (Fig. $8 A$ ). When the synaptic component predominates, however, LG's maximum spike frequency occurs later, after GM has begun to fire (Fig. 8B; see also Fig. 13C). Correlatively, the phase relationships of LG and DG (a medial tooth return stroke motor neuron, the antagonist of $\mathrm{GM}$ ) are altered. When LG's endogenous component is apparent, LG and DG firing overlaps considerably (Fig. $8 \mathrm{~A}$ ); when the synaptic component underlies all of LG's firing, these 2 neurons are completely out of phase and show little overlap (Fig. $8 B$ ).

\section{Modulation of LG's composite discharge by $A P M$}

We have found that an identified modulatory interneuron, the APM (Nagy et al., 1981), can control LG's composite discharge by separately and selectively altering LG's 2 firing segments. Through these alterations of LG's discharge, APM shifts the phase relationships within the gastric mill network.

Regardless of the preexisting pattern of activity in LG, a discharge of APM always results in a pattern in which the synaptic component overwhelmingly predominates, the endogenous component generally being entirely absent. A bricf discharge of APM which occurs during gastric activity in which LG is ex- 


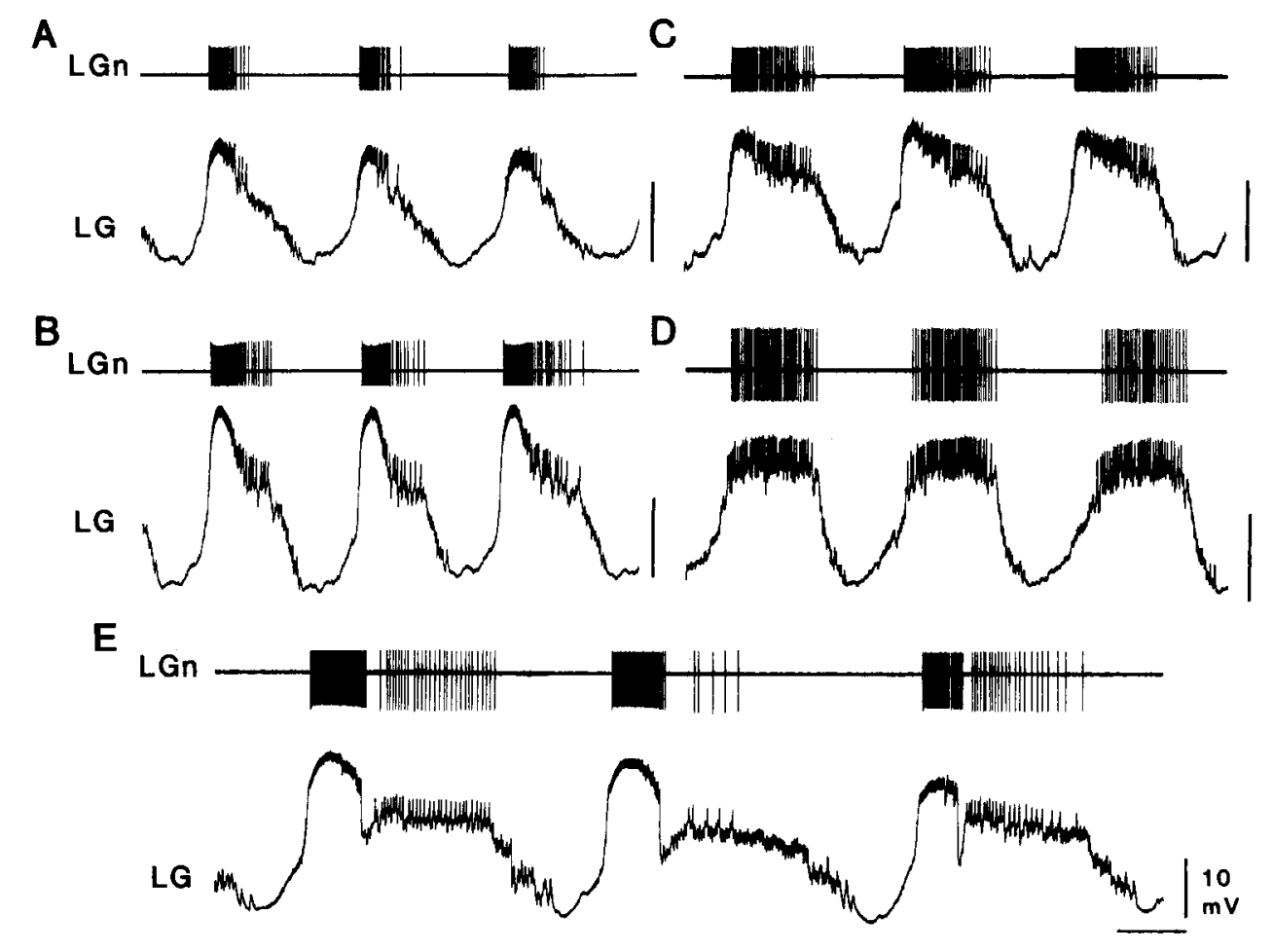
importance of the endogenous and synaptic components can markedly change the form of the LG discharge. $A-D$, These recordings ( $A-C$ from the same preparation) demonstrate the range of variation, from almost complete dominance of the endogenous component $(A)$ to the total absence of the endogenous component $(D) . E$, A case in which the endogenous and synaptic components are sufficiently separated in time that LG presents a double burst. Spike frequency is always higher during the endogenous segment than during the synaptic segment. Calibrations: horizontal bar, $2 \mathrm{sec}$; vertical bars, $10 \mathrm{mV}$.
Figure 6. Variations in the relative

hibiting both the endogenous and synaptic segments of its discharge produces a long-lasting switch to an LG activity in which the endogenous segment is absent (Fig. 9). Thus, APM appears to suppress the endogenous component of LG activity and simultaneously to enhance the synaptic component (Figs. 9, 10).

When LG is active, but the endogenous component of its discharge is absent (Fig. 10A1; note that LG is firing in phase with GM), APM activity, while accelerating and enhancing the overall gastric rhythm (Dickinson et al., 1987), does not alter the form of LG's discharge; instead, it simply increases the intensity of LG's synaptic component (Fig. 10.42). This enhancement comes about through the activation of the presynaptic elements, the CG neurons which produce the epsps responsible for the synaptic excitation of LG (Fig. 10, $B, C$; see also Dickinson et al., 1987). In Figure $10 C$, for example, a considerable increase in the frequency of the epsps recorded simultaneously in LG and in the GM neurons is seen $1.5 \mathrm{sec}$ after an APM discharge (compare Figs. $10 \mathrm{Cl}$ and 10C2).

Finally, when the gastric network is silent, a single burst in APM induces a gastric rhythm in which the endogenous segment of LG's discharge is conspicuously absent, and the synaptic component alone underlies the rhythmic bursts of action potentials recorded in LG (Fig. 11). This corresponds to the fact that, when APM induces rhythmic gastric activity, the volleys of epsps which LG receives from the CG neurons become rhythmic and increase in intensity.

Activity in the modulatory neuron APM thus leads to a particular type of LG discharge, specifically one in which the endogenous component is absent and the synaptic component is quite strong.

Because the type of discharge seen in LG plays an important role in determining the phase relationships within the gastric mill network, the modulatory neuron APM, by controlling the form of LG's discharge, is able to exert control over the phase relationships in the network (Figs. 12, 13). By switching LG's composite discharge from one with an important endogenous component to one in which the synaptic component predominates, APM provokes changes in phase relationships both within the medial tooth subsystem (Fig. 12) and between the medial and lateral tooth subsystems (Fig. 13). Before the discharge of APM (Fig. 12A), firing in LG precedes the onset of the burst in MG; the phase of MG in the LG period is 0.1. After APM fires (Fig. 12B), LG starts firing after MG, the phase of MG in the LG period now being -0.1 . Likewise, in the absence of APM firing, the lateral tooth power stroke neuron LG begins to fire well ahead of the power stroke neuron of the medial tooth, GM (Fig. 13, $A, B$ ). Activity in APM, however, by altering the form of LG's discharge, changes these relative phases such that the 2 power stroke neurons fire in synchrony (Fig. 13, $A, C$ ).

Consequently, by selectively altering specific components of the sequential composite discharge of a single neuron (the $L G$ motor neuron) in the gastric pattern generator, APM can extensively modify the gastric motor pattern and can, in effect, switch it from one type of motor output to another.

\section{Discussion}

\section{$L G$ 's composite discharge and flexibility in the gastric mill} pattern

Modifications of both cellular properties and synaptic interactions have been implicated in the control and modulation of rhythmic motor patterns (Selverston and Moulins, 1985; Kaczmarek and Levitan, 1987). However, the contributions of endogenous properties and synaptic potentials to the discharge of a neuron are often difficult to distinguish because they occur more or less simultaneously. The case of the LG neuron, described here, differs from those previously described in that the 2 components, regenerative membrane properties and synaptic input, contribute to its discharge sequentially rather than simultaneously. Each component thus clcarly contributes to the generation of action potentials and helps determine the timing 
of its bursts of action potentials. Because the 2 components of LG's discharge can be separately modulated, a wide range of firing patterns can be generated by this neuron. Such composite discharges likely exist and increase the flexibility of other pattern-generating networks as well.

A number of recent studies have suggested that motor patterns are flexible not only in the frequency, duration, and intensity of bursts in individual elements of the pattern, but also in the phase relationships that exist among those elements (Nagy and Dickinson, 1983; Marder, 1984; Moulins and Nagy, 1985; Getting, 1988; Harris-Warrick, 1988; Marder et al., 1987). Several mechanisms for altering phase relationships within a pattern generator have already been demonstrated. The factor ultimately responsible for these modifications is a change (or changes) in the relative importance of specific synapses. In the stomatogastric system, for example, when 2 neurons are connected by both inhibitory synapses and electrical coupling, changes in the relative importance of the 2 types of synapse can substantially alter the phase relationships of those 2 neurons, and consequently of other neurons that rely on them for timing. Such changes were predicted on theoretical grounds by Mulloney et al. (1981) and were first demonstrated in the pyloric network of the stomatogastric system, for the $\mathrm{AB}$ and VD neurons. After a brief discharge of the modulatory neuron APM, the efficacy of the electrical coupling between these 2 neurons is lastingly increased, leading to prolonged phase shifts (Nagy and Dickinson, 1983).

A second previously described mechanism for producing phase shifts in the stomatogastric nervous system also involves the pyloric network. Eisen and Marder (1984) showed that the phases of certain neurons can be altered by a change in the relative activity of 2 co-active presynaptic neurons that are electrically coupled but release different transmitters. Flexibility derives from the facts that (1) the time courses of the response to these 2 transmitters differ and (2) the relative levels of activity of the 2 coupled presynaptic neurons can be selectively altered by modulatory inputs. Thus, even in the absence of a change in the timing of transmitter release, the timing of the inhibition can change, resulting in phase shifts (Eisen and Marder, 1984; Marder and Eisen, 1984a, b).

Changes in the relative importance of the 2 components determining the composite discharge of the LG neuron provide a third mechanism that can produce phase shifts between the discharges of 2 neurons. Because the 2 components of LG's discharge produce substantially different spike frequencies, the modulatory neuron APM, by altering the magnitudes of those components, effectively alters the relative importance of the electrical versus inhibitory synapses between $\mathrm{LG}$ and $\mathrm{MG}$, the 2 power stroke neurons of the lateral teeth. When the plateau phase is stronger, spike frequency is higher and the inhibition predominates; when the synaptic phase is predominant, action potential frequency is low and the electrical coupling is stronger. This results in shifts in the phases of the 2 neurons' activities. In this case, the characteristics of the presynaptic discharge, more than its timing, determine the changes in phase relationships.

In the gastric mill CPG, the LG neuron plays a pivotal role in the coordination both of the lateral tooth subsystem and of the 2 subsystems with respect to one another (Russell, 1985b, 1987 ). Because of this, changes in its phase can affect a variety of other phases; not only are the 2 power stroke neurons of the lateral teeth (LG and MG) phase-shifted, but relations of the

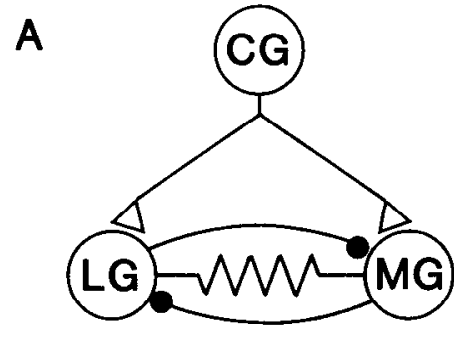

B

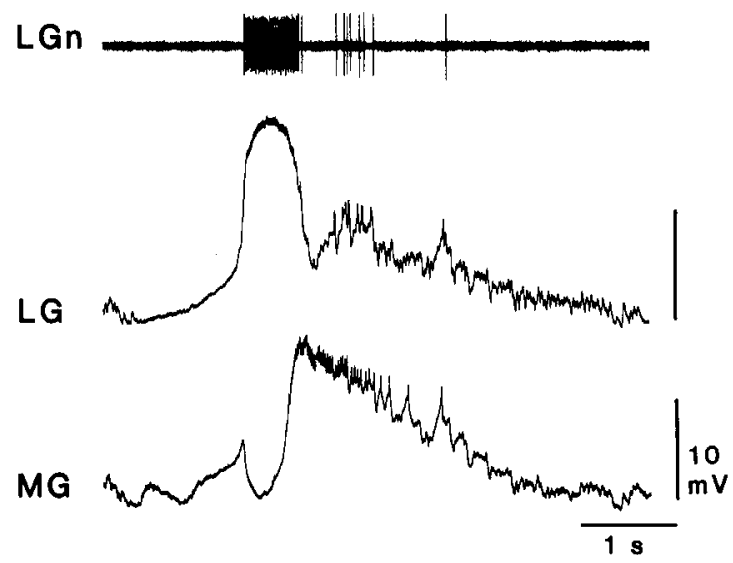

C
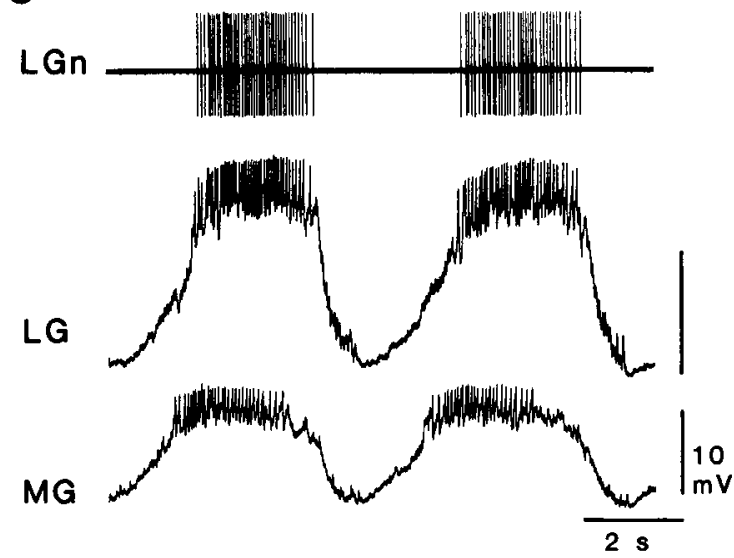

Figure 7. Changes in the relative importance of the endogenous and synaptic components of LG's discharge lead to changes in phase relationships within the lateral tooth subsystem of the gastric motor pattern. $A$. Schematic diagram of the synaptic relationships of the 2 power stroke neurons of the lateral teeth, MG and LG, and the $C G$ neuron. For explanation of symbols, see legend of Figure 1.B, When the endogenous component is strong, LG fires rapidly and inhibits MG. After the endogenous segment of LG firing, MG is released and can inhibit LG. LG and $M G$ then receive common synaptic input from the $C G$ neuron and fire together. LG firing leads MG by approximately $0.5 \mathrm{sec} C$, When the cndogenous component in LG is absent, LG fires at lower frequency and its inhibition of MG is ineffective. $L G$ and $M G$ fire more or less together during LG's synaptic segment, with MG leading slightly. Calibrations: horizontal bars, $1 \mathrm{sec}$ in $B, 2 \mathrm{sec}$ in $C$; vertical bars, $10 \mathrm{mV}$.

lateral to the medial teeth are simultaneously shifted (Dickinson et al., 1987). Thus, the inherent flexibility provided by a composite discharge like that found in $\mathrm{LG}$ is particularly important in that changes in the balance between its components can contribute substantially to alterations of the entire motor pattern.

Pattern generators in general may be capable of producing 
A
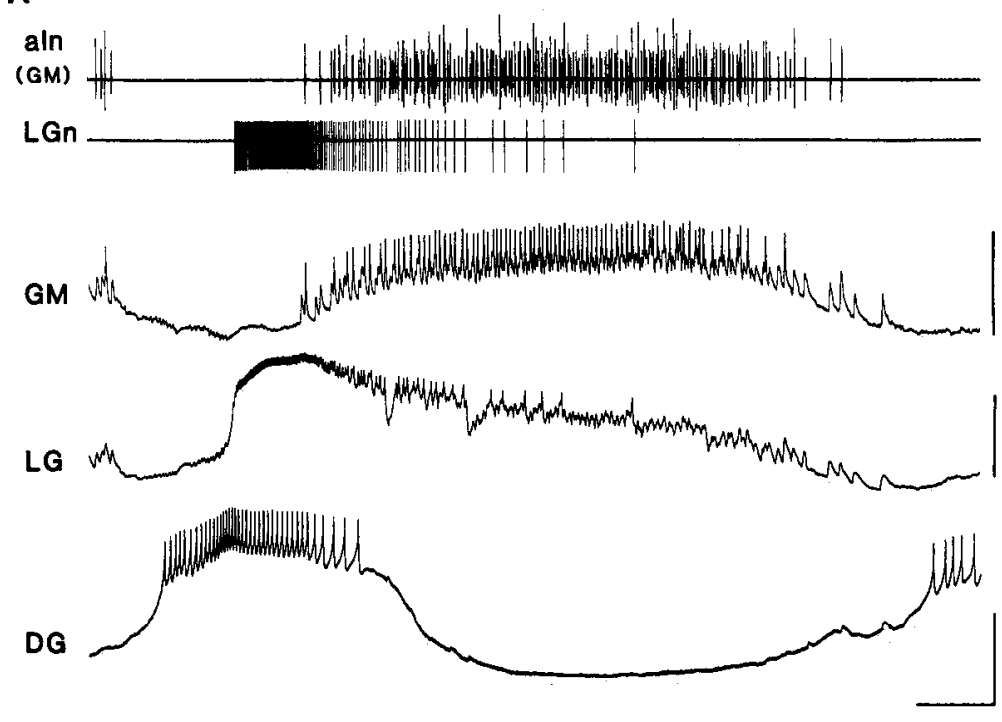

B

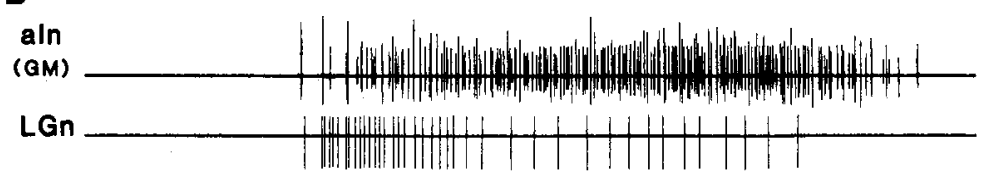
portance of the endogenous and synaptic components of LG's discharge lead to changes in phase relationships between the neurons of the lateral and medial tooth subsystems. $A$, When the endogenous component of LG's discharge is strong, LG begins firing well before the medial tooth neuron GM and overlaps considerably with the medial tooth return stroke neuron DG. aln, extracellular recording of the activity of the 4 GM neurons. $B$, When only the synaptic component of LG's discharge is present, LG and GM start firing simultaneously, and no overlap between LG and DG occurs. $A$ and $B$, from the same experiment. Calibrations: horizontal bars, $1 \mathrm{sec}$; vertical bars, $10 \mathrm{mV}$.

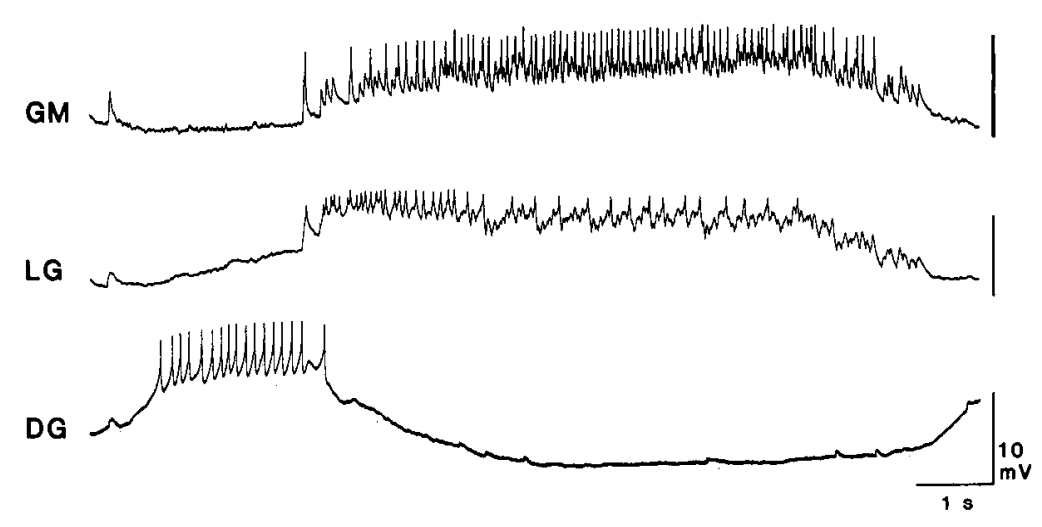

multiple outputs, and thus may be relatively fiexible networks (Marder, 1984; Getting and Dekin, 1985; Marder et al., 1987; Sossin et al., 1987). A useful concept in this light is the notion that pattern generators may be constructed of "building blocks" (Getting, 1988), which, under the influence of different modulatory substances, can be put together in a number of ways to generate a variety of motor outputs. Several such building blocks, including synaptic relations within the network, cellular properties of individual neurons, rhythmic synaptic inputs from outside the network, and postinhibitory rebound, have been considered in past examinations of the gastric mill network (Mulloney and Selverston, 1974a, b; Selverston and Mulloney, 1974; Russell, 1976; Selverston et al., 1976; Russell and Hartline, 1978, 1984; Robertson and Moulins, 1981, 1984; Dickinson et al., 1987; Selverston, 1987). The flexible composite discharge of LG might be considered as an additional building block. The form of the discharge in LG, in parallel with the synapses, can determine to a large extent the manner in which synaptic relations are expressed and must therefore be considered as one of the determinants of phase relationships both within the lateral tooth system and between the lateral and medial tooth subsystems.

Modulation of LG's composite discharge by APM: a possible mechanism for switching between 2 gastric mill behaviors

Regardless of the initial activity pattern in LG, its firing pattern after an APM discharge is always similar. Its plateau phase is suppressed, presumably by an effect on the LG neuron itself (although we cannot rule out the possibility of an interposed interneuron); and the synaptic phase is emphasized, by an augmentation of the presynaptic input to the pattern generator. This, in combination with effects of APM on the other gastric mill neurons (see Dickinson et al., 1987), leads to a particular gastric motor pattern, characterized by a given set of phase relationships. Specifically, the LG, MG, and GM neurons are nearly in phase, and the DG and AM are out of phase with the first group. Consequently, APM activity always generates a specific variant of the gastric pattern.

Recent work of Heinzel and Selverston (Heinzel, 1987, 1988a, 
A
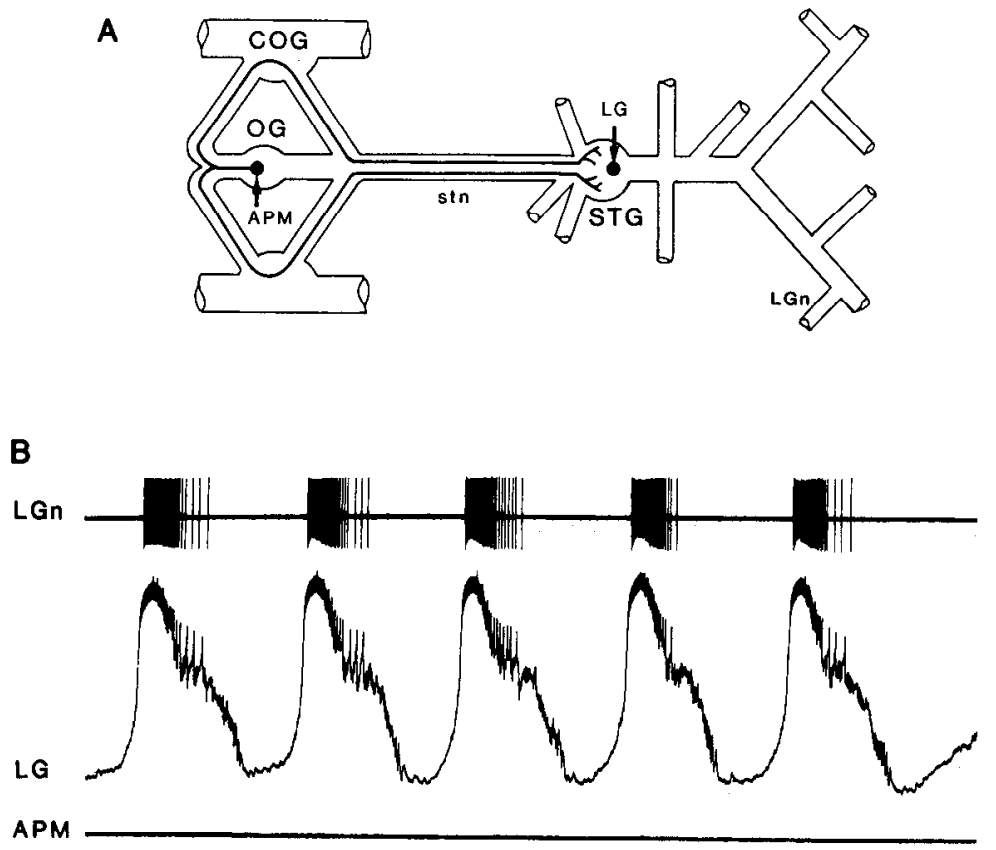

C
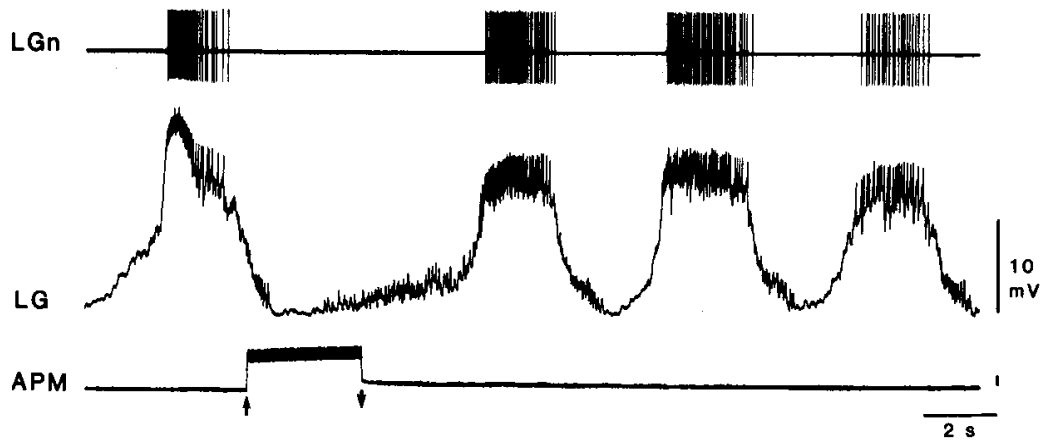

Figure 9. The modulatory neuron APM can change the LG discharge from one in which both the endogenous and synaptic components are evident to one in which only the synaptic component is present. $A$, Diagram of the preparation, showing the APM neuron. $B$, The IG discharge before APM fires; spike frequency is first high (during the endogenous segment), then low (during the synaptic segment). The plateau phase clearly predominates. $C$, When APM fires (current injection, arrows), the endogenous component is suppressed and the synaptic component is enhanced. The spike frequency in LG is now lower and is uniform throughout the burst. This change is long-lasting. Calibrations: horizontal bars, $2 \mathrm{sec}$; vertical bars, $10 \mathrm{mV}$. b; Heinzel and Selverston, 1988) suggest a possible behavioral significance of these effects of APM. In studies of California spiny lobsters (Panulirus interruptus), Heinzel (1988a, b) was able to discern 2 major patterns of gastric mill tooth activity, which he called the "squeeze" and the "cut and grind." The neuronal discharges expected to produce these movement patterns roughly correspond to the 2 major variants of the gastric rhythm that we record (e.g., Fig. 8). To aid in understanding the role APM's modulation of LG might play in behavioral control, we briefly summarize the 2 behavioral modes seen by Heinzel (1988a, b).

In the "squeeze" mode, the 3 teeth ( 2 lateral, 1 medial), come together simultaneously, with the lateral teeth showing only transverse movement (no anterior-posterior movement) and the medial tooth moving forward. This entails simultaneous contraction of the muscles associated with the LG, MG, and GM neurons. The 3 teeth stay together briefly, then return more or less synchronously to their original positions, driven by the synchronous contractions of the muscles controlled by DG, AM, and LPG. They remain in this position until the start of the next cycle (Heinzel, 1988a, b).

The "cut and grind" mode of gastric mill movements begins with forward and medial movements of the 2 lateral teeth. They move to the point of touching (at the anterior end), then rotate so as to bring the posterior part of the teeth together as well. This would be accomplished by contraction of the LG muscle, followed by co-contraction of the LG- and MG-controlled muscles. The 2 lateral teeth then move caudally (still touching), while the medial tooth moves forward, scraping across them. During this phase, the muscles controlled by LG, MG, and GM would all contract. Finally, they return to their resting, open position, driven by contraction of the return stroke muscles, controlled by DG, AM, and LPG (Heinzel, 1988a, b).

In the isolated Palinurus (red lobster) nervous system studied here, we see 2 common variants of the gastric motor pattern; they correspond to what would be expected to produce a "squeeze" and a "cut and grind" mode in the resulting behavioral sequence. These 2 modes correspond respectively to the gastric patterns in which LG's composite discharge includes only the synaptic phase and in which both the plateau and synaptic phases are present. When LG has no plateau phase, the LG, MG, and GM neurons fire in phase, which would be expected to produce a "squeeze" movement. In contrast, when the plateau and synaptic phases are both strong, LG fires at a high frequency before either of the other neurons begins to fire. $M G$ then joins it, followed shortly by the GM neurons, so that the LG, MG, and GM neurons show a period of coactivation. Such a pattern would be expected to produce a "cut and grind" movement. 

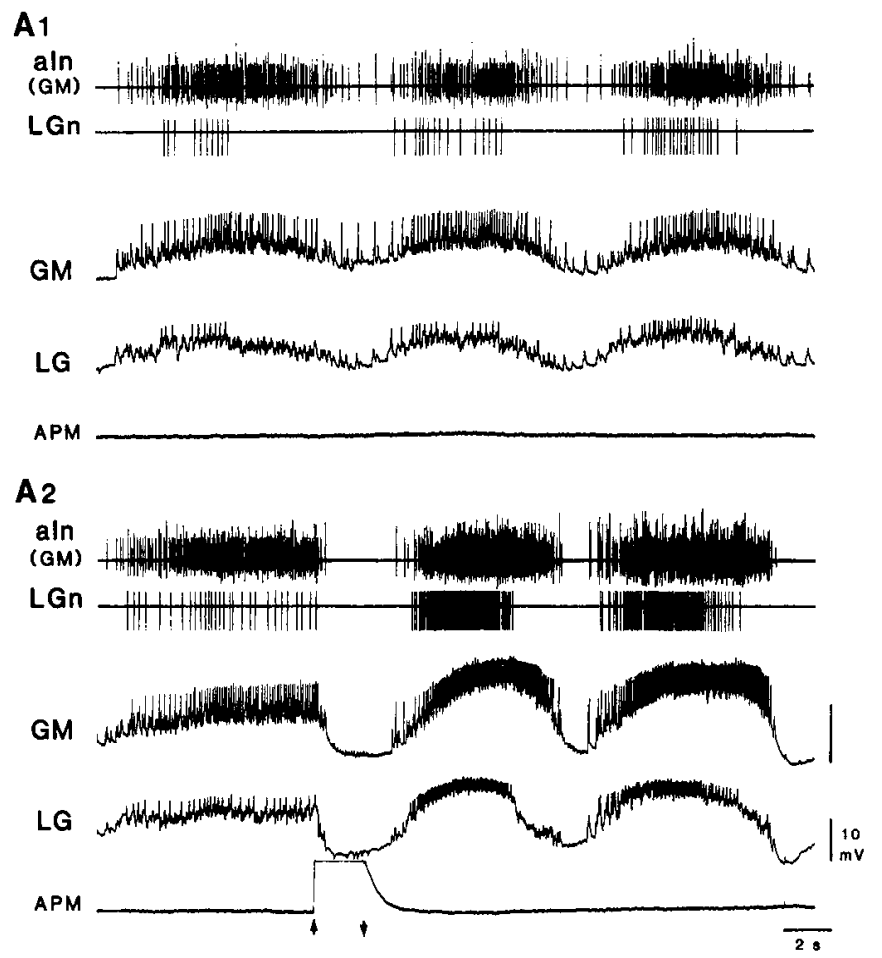

B

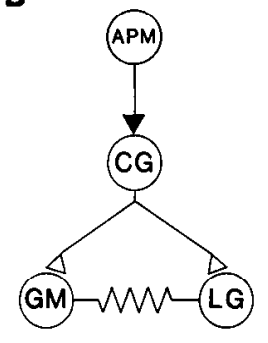

C1
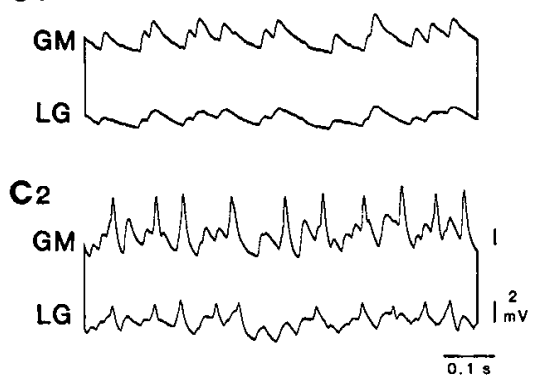

Figure 10. Activity in APM enhances the synaptic component of LG's discharge. $A$, The LG neuron can spontaneously present a discharge in which only the synaptic component of its discharge is present $(A I)$. The barrage of epsps it receives from the CG neuron occurs simultaneously in a GM neuron. A brief discharge of APM (elicited by current injection, arrows) considerably increases the frequency of the simultaneous epsps (from the CG neuron) in LG and in GM ( $A 2$; see also $C 1$ and $C 2$ ). During the depolarization of APM, the amplifier was saturated and APM's discharge was not recorded. $B$, Schematic diagram of the syn-
In the intact animal (Panulirus), Heinzel (1988a, b) has seen spontaneous transitions between the 2 modes, as well as other variants of these movement patterns, indicating that on the behavioral level, the gastric mill system is highly flexible. A comparable variety of patterns has been recorded in the gastric mill muscles of freely moving Palinurus (E. Rezer, personal communication). On the neuronal level, this flexibility can be at least partly explained by the flexible nature of the composite discharge in LG. In the LG neuron, we see not only the 2 common patterns of discharge (synaptic phase only; plateau and synaptic phases), which correspond to the 2 major modes of gastric mill movement, but also a variety of intermediate cases (see Fig. 6), which might correspond to the other behavioral patterns recorded in the intact animal. For example, Heinzel $(1987,1988 \mathrm{a}, \mathrm{b})$ reports cases in which the lateral teeth close twice during a single medial tooth movement; this would require a double burst in the lateral tooth power stroke neurons. Such a double burst in $\mathrm{LG}$ is seen in a number of recordings (e.g., Fig. $6 E$ ), in which the plateau and synaptic phases of LG's discharge are separated more than usual.

The functional result of activity in the APM neuron can now be considered more fully. Activity in the APM neuron can activate the entire gastric rhythm. APM can also modulate an ongoing gastric rhythm. But the specific variant of the rhythm that is produced when APM fires is always the same, that is, a pattern in which LG's plateau phase of firing is minimal or absent and in which the synaptic phase is substantial. We thus suggest that in the intact animal, activity in APM provokes a "squeeze" mode of behavior, whether starting from a gastric mill that is resting, one that is already "squeezing," or one that is "cutting and grinding." Because previous studies have suggested that APM is cholinergic (Nagy and Dickinson, 1983), we suggest that the switches between behavioral outputs of this system can be controlled by at least 2 neuromodulators: $\mathrm{ACh}$ (acting in large part on LG) might produce a "squeeze" mode,

\section{$\longleftarrow$}

aptic relations of the APM, CG, LG, and GM neurons. For explanation of symbols, see legend of Figure 1. $C$, Higher-speed recordings of the simultaneous epsps in $\mathrm{LG}$ and $\mathrm{GM}$ before $(\mathrm{Cl}$, corresponds to $\mathrm{Al})$ and after $(C 2$, corresponds to $A 2)$ an APM discharge. Calibrations: horizontal bars, $2 \mathrm{sec}$ in $A, 0.1 \mathrm{sec}$ in $C$; vertical bars, $10 \mathrm{mV}$ in $A, 2 \mathrm{mV}$ in $C$.
Figure 11. When the gastric network is silent, a brief discharge of APM (elicited by current injection, arrows) lastingly activates the rhythm, but the LG discharge is still sustained entirely by the synaptic component. The firing pattern in LG resembles that seen when APM acts on an already active rhythm (compare with Fig. 9C). aln, extracellular recording of the activity of the 4 GM neurons. Calibrations: horizontal bars, $2 \mathrm{sec}$; vertical bars, $10 \mathrm{mV}$.

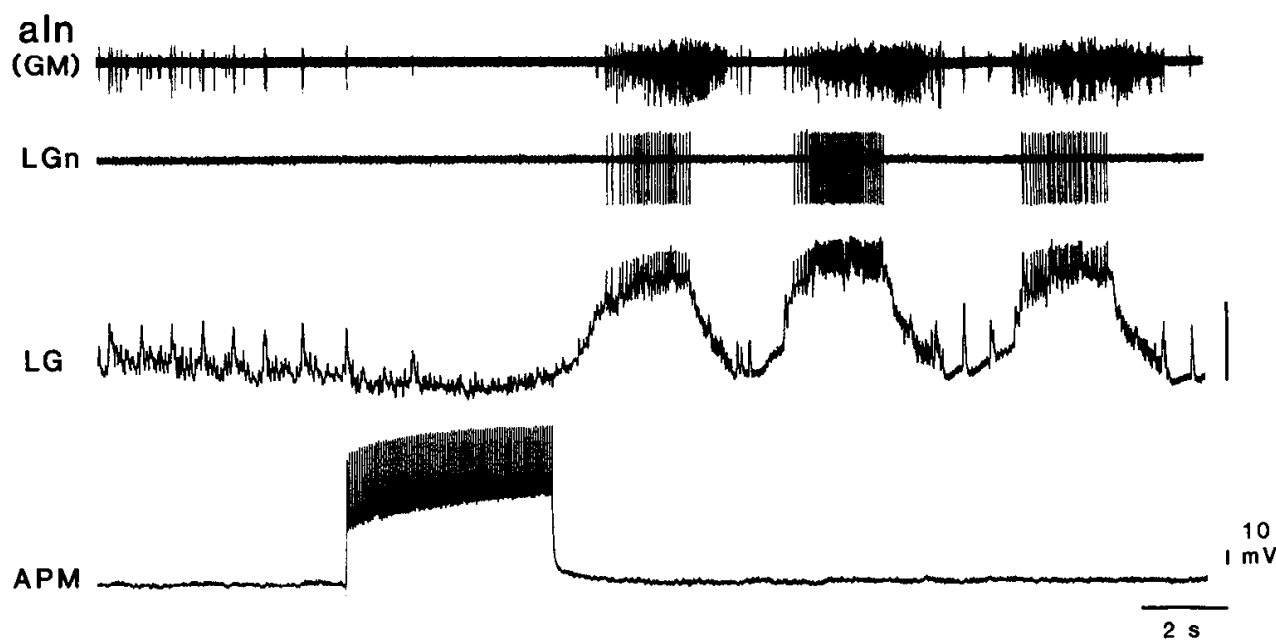


A

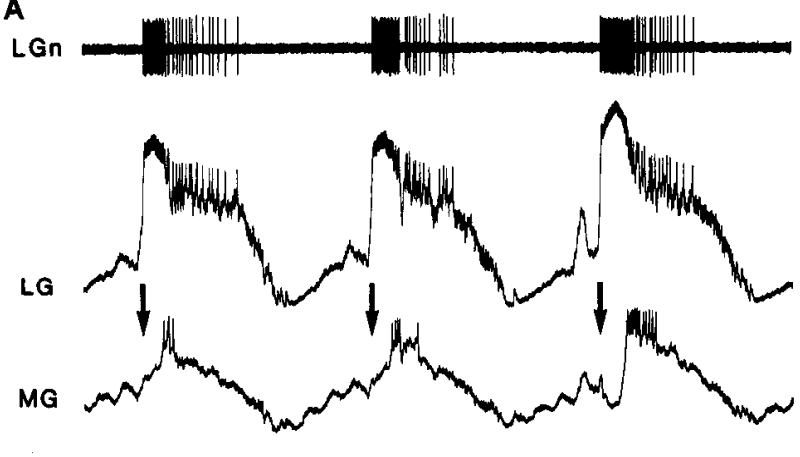

APM

B

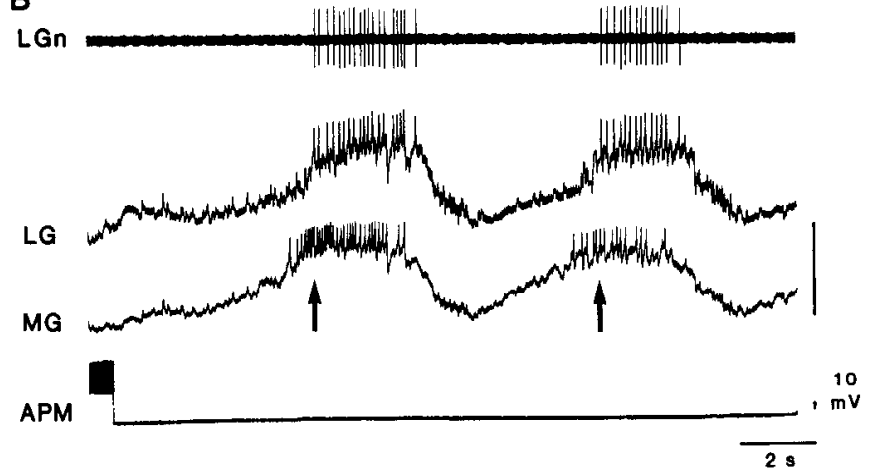

Figure 12. Activity in APM, by altering LG's discharge, changes the phase relationships between the 2 lateral tooth power stroke neurons, LG and MG. $A$, Before APM fires, LG's discharge has a strong endog- whereas proctolin (Heinzel, 1987, 1988a) would cause a "cut and grind" mode.

Consequently, the inherent variability of a composite discharge in a neuron of a CPG provides a means by which that pattern generator can produce 2 or more distinct behavioral pallerns. The ability of a modulatory neuron to exert selective control over those different phases provides a mechanism by which the motor output can be switched from one pattern, and hence one behavior, to another.

\section{References}

Dickinson, P. S., F. Nagy, and M. Moulins (1987) An identified neuron in Crustacca which modulates one pattern gencrator, the pyloric network, also activates the gastric mill network. J. Exp. Biol. (in press).

Eisen, J. S., and E. Marder (1982) Mechanisms underlying pattern generation in lobster stomatogastric ganglion as determined by selective inactivation of identified neurons. III. Synaptic connections of electrically coupled pyloric neurons. J. Neurophysiol 48: 1392-1415.

Eisen, J. S., and E. Marder (1984) A mechanism for the production of phase shifts in a pattern generator. J. Neurophysiol. 51: 13741393.

Getting, P. A. (1988) Comparative analysis of invertebrate central pattern generators. In Neural Control of Rhythmic Movements, A. H. Cohen, S. Rossignol, and S. Grillner, eds., pp. 101-127, Wiley, New York

Getting, P. A., and M. S. Dekin (1985) Tritonia swimming: A model system for integration within rhythmic motor systems. In Model Neural

enous component, and the onset of firing in LG (arrow) considerably precedes MG firing. $B$, After an APM discharge (elicited by current injection), the endogenous component of LG's discharge is suppressed and its synaptic component alone drives action potentials. LG now starts firing only after the onset of activity in MG. Calibrations: horizontal bars, $2 \mathrm{sec}$; vertical bars, $10 \mathrm{mV}$.

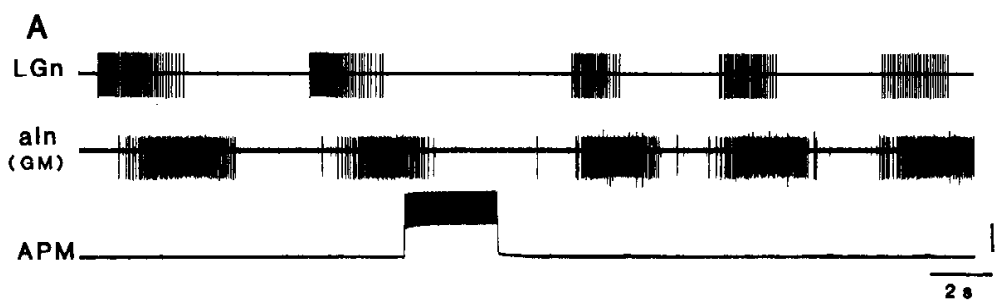

B

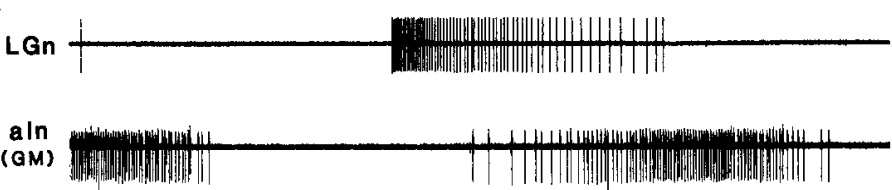

APM

C
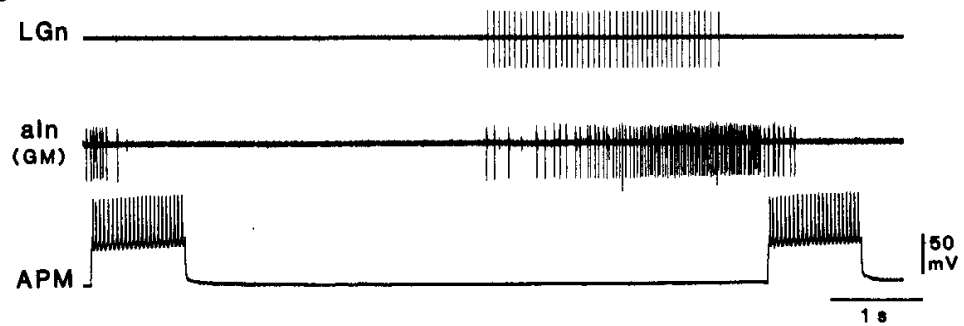

Figure 13. Activity in APM alters the phase relationships between the lateral tooth neuron LG and the medial tooth neuron GM by altering LG's composite discharge. $A$, Before an APM discharge, LG activity precedes GM firing; when APM fires (due to current injection), the 2 neurons become synchronized. This effect is long-lasting. The form of LG's composite discharge is altered concurrently; this is reflected in the changes in the evolution of LG spike frequency within bursts. $B$ and $C$, Higher-speed recordings from the same preparation as in $A$ to show more clearly the phase relationships before $(B)$ and during $(C)$ APM activity. In the absence of APM, LG precedes GM. When APM fires, LG and $\mathrm{MG}$ fire in synchrony. Calibrations: horizontal bars, $2 \mathrm{sec}$ in $A, 1 \mathrm{sec}$ in $B$ and $C$; vertical bars, $50 \mathrm{mV}$. 
Networks and Behavior, A. Selverston, ed., pp. 3-20, Plenum, New York.

Harris-Warrick, R. M. (1988) Chemical modulation of central pattern generators. In Neural Control of Rhythmic Movements, A. H. Cohen, S. Rossignol, and S. Grillner, eds., pp. 285-331, Wiley, New York.

Hartline, D. K. (1979) Pattern generation in the lobster (Panulirus) stomatogastric ganglion. I. Pyloric network simulation. Biol. Cybern. 33: $223-236$.

Heinzel, H. G. (1987) Spontaneous and proctolin-induced modes of operation of the isolated gastric oscillator and of the gastric mill in the intact animal. In The Crustacean Stomatogastric System, A. I. Selverston and M. Moulins, eds., pp. 175-180, Springer-Verlag, New York.

Heinzel, H. G. (1988a) Gastric mill activity in the lobster. I. Spontaneous modes of chewing. J. Neurophysiol. 59: 528-550.

HeinzeI, H. G. (1988b) Gastric mill activity in the lobster. II. Proctolin and octopamine initiate and modulate chewing. J. Neurophysiol. 59. 551-565.

Heinzel, H. G., and A. I. Selverston (1988) Gastric mill activity in the lobster. III. The effects of proctolin on the isolated central pattern generator. J. Neurophysiol. 59: 566-585

Kaczmarek, L. K., and I. B. Levitan (1987) Neuromodulation: The Biochemical Control of Neuronal Excitability, Oxford U. P., New York.

Marder, E. (1984) Mechanisms underlying neurotransmitter modulation of a neuronal circuit. TINS 7: 48-53.

Marder, E., and J. S. Eisen (1984a) Transmitter identification of pyloric neurons: Electrically coupled neurons use different transmitters. J. Neurophysiol. 51: 1345-1361.

Marder, E., and J. S. Eisen (1984b) Electrically coupled pacemaker neurons respond differently to same physiological inputs and neurotransmitters. J. Neurophysiol. 51: 1362-1373.

Marder, E., S. L. Hooper, and J. S. Eisen (1987) Multiple neurotransmitters provide a mechanism for the production of multiple outputs from a single neuronal circuit. In Synaptic Function, G. M. Edelman, W. E. Gall, and W. M. Cowan, eds., pp. 305-327, Wiley, New York

Maynard, D. M., and M. R. Dando (1974) The structure of the stomatogastric neuromuscular system in Callinectes sapidus, Homarus americanus, and Panulirus argus (Decapoda Crustacea). Phil. Trans. R. Soc. London [Biol.] 268: 161-220.

Miller, J. P. (1987) Pyloric mechanisms. In The Crustacean Stomatogastric System, A. I. Selverston and M. Moulins, eds., pp. 109-136, Springer-Verlag, New York.

Moulins, M., and F. Nagy (1981) Participation of an unpaired motor neurone in the bilaterally organized oesophageal rhythm in the lobsters Jasus lalandii and Palinurus vulgaris. J. Exp. Biol. 90: 205-230.

Moulins, M., and F. Nagy (1985) Extrinsic inputs and flexibility in the motor output of the lobster pyloric neural network. In Model Neural Networks and Behavior, A. I. Selverston, ed., pp. 49-68, Plenum, New York.

Mulloney, B. (1987) Neural circuits. In The Crustacean Stomatogastric System, A. I. Sclverston and M. Moulins, eds., pp. 57-75, SpringerVerlag, New York.

Mulloney, B., and A. I. Selverston (1974a) Organization of the stomatogastric ganglion in the spiny lobster. I. Neurons driving the lateral teeth. J. Comp. Physiol. 91: 1-32.
Mulloney, B., and A. I. Selverston (1974b) Organization of the stomatogastric ganglion of the spiny lobster. III. Coordination of the two subsets of the gastric system. J. Comp. Physiol. 91: 53-78.

Mulloney, B., D. H. Perkel, and R. W. Budelli (1981) Motor pattern production: Interaction of chemical and electrical synapses. Brain Res. 229: 25-33

Nagy, F., and P. S. Dickinson (1983) Control of a central pattern generator by an identified modulatory interneurone in Crustacea. I. Modulation of the pyloric motor output. J. Exp. Biol. 105: 167-173.

Nagy, F., P. S. Dickinson, and M. Moulins (1981) Modulatory effects of a single neuron on the activity of the pyloric pattern generator in Crustacea. Neurosci. Lett. 23: 167-173.

Robertson, R. M., and M. Moulins (1981) Control of rhythmic bchaviour by a hierarchy of linked oscillators in crustacea. Neurosci. Lett. 21: $111-116$.

Robertson, R. M., and M. Moulins (1984) Oscillatory command input to the motor pattern generators of the crustacean stomatogastric ganglion. II. The gastric rhythm. J. Comp. Physiol. 154: 673-691.

Russell, D. F. (1976) Rhythmic excitatory inputs to the lobster stomatogastric ganglion. Brain Res. 101: 598-602.

Russell, D. F. (1985a) Pattern and reset analysis of the gastric mill rhythm in a spiny lobster, Panulirus interruptus. J. Exp. Biol. 114 71-98.

Russell, D. F. (1985b) Neural basis of teeth coordination during gastric rhythms in spiny lobsters, Panulirus interruptus. J. Exp. Biol. 114: 99-119.

Russell, D. F. (1987) How many generators in the gastric mill system? In The Crustacean Stomatogastric System, A. I. Selverston and M Moulins, eds., pp. 171-175, Springer-Verlag, New York.

Russell, D. F., and D. K. Hartline (1978) Bursting neural networks: A reexamination. Science 200: 453-456.

Russell, D. F., and D. K. Hartline (1984) Synaptic regulation of cellular properties in burst oscillations of neurons in gastric mill system of spiny lobster Panulirus interruptus. J. Neurophysiol. 52: 54-73.

Selverston, A. I. (1987) Gastric mill mechanisms. In The Crustacean Stomatogastric System, A. I. Selverston and M. Moulins, eds., pp. 147-171, Springer-Verlag, New York.

Selverston, A. I., and M. Moulins (1985) Oscillatory neural networks. Annu. Rev. Physiol. 47: 29-48.

Selverston, A. I., and M. Moulins (1987) Comparison with other systems. In The Crustacean Stomatogastric System, A. I. Selverston and M. Moulins, eds., pp. 307-313, Springer-Verlag, New York.

Selverston, A. 1., and B. Mulloney (1974) Organization of the stomatogastric ganglion of the spiny lobster. II. Neurons driving the medial tooth. J. Comp. Physiol. 91: 33-51.

Selverston, A. I., D. F. Russell, J. P. Miller, and D. G. King (1976) The stomatogastric nervous system: Structure and function of a smal neural network. Prog. Neurobiol. 7: 215-290.

Sossin, W. S., M. D. Kirk, and R. H. Scheller (1987) Peptidergic modulation of neuronal circuitry controlling feeding in Aplysia. J. Neurosci. 7: 671-681.

Weeks, J. C. (1981) The neuronal basis of leech swimming: Separation of swim initiation, pattern generation, and intersegmental coordination by selective lesions. J. Neurophysiol. 45: 698-723. 